\title{
OBSERVATIONS ON THE USE OF NOVASUROL IN EDEMA DUE TO HEART FAILURE
}

\author{
By J. HAMILTON CRAWFORD, AND J. F. MCINTOSH \\ (From the Hospital of The Rockefeller Institute for Medical Research, New York)
}

(Received for publication, November 28,1924)

Novarsurol is an organic compound containing mercury, which was introduced by the Bayer company as an antisyphilitic agent. Its therapeutic use in this disease was first described by Zeiler (1917). Its constitution is sodium oxymercuric-ortho-chlorphenol-oxylacetate with diethylmalonylurea and may be represented as follows (White, 1924):<smiles>CCCC1(CCC)C(=O)NOC(=O)NC1=O</smiles>

It is prepared for use as a 10 per cent neutral sterile solution. The marked incidental diuretic action caused by its administration was noted soon after its introduction, especially in those cases in which considerable edema had developed. Its use as a diuretic in cases other than those of syphilitic origin was naturally suggested by this occurrence.

It has been known for a long time that the administration of mercury produces diuresis. Even as early as 1799 Ferriar stated that the diuretic action of digitalis was increased when given in conjunction with calomel. Jendrassik $(1886,1891)$ was the first to draw attention to the striking effects that could be produced by the use of calomel alone. He administered repeated small doses by mouth and obtained a remarkable diuresis in cases of edema. This treatment was in vogue for some time but gradually became much less used as different observers reported deleterious after effects on the kidney. There has been a good deal of debate as to the mechanism by which this 
diuresis is produced. The majority of observers now, as is seen in Cushny's (1917) review of the literature, favor the view that it acts directly on the kidney.

Novasurol has already been used in many types of edema. It has apparently no effect on inflammatory exudates. Practically all observers are agreed that it is contra-indicated in renal disease. In the ascites due to cirrhosis of the liver and carcinoma, reports of the results obtained vary considerably. In heart disease on the other hand remarkable results have been described by several observers. The first account of its use as a diuretic was given by Saxl and Heilig (1920). They obtained diuresis up to three liters by giving 1 to $2 \mathrm{cc}$. by intramuscular injection, and the patients lost weight corresponding to the diuresis. The chloride in the urine was increased both in total quantity and in concentration. The injection of atropine inhibits the diuresis. In a small number of their cases troublesome attacks of diarrhea developed. No evidence of kidney damage occurred. The fact that this drug can remove edema which had resisted the usual forms of medication has been confirmed by several observers. The increase in chloride output has also been confirmed by all who have studied this point. Saxl and Heilig (1920) in addition found that the total quantity of nitrogen excreted in the urine was unaltered. Mühling (1921) states that the total nitrogen, urea and creatinin in the urine were increased. He says this increase may occur one or two days later than the other effects.

The mechanism by which novasurol acts has aroused a considerable amount of controversy. Saxl and Heilig (1922) believe that the action is on the extra renal tissues. They studied the protein content of the plasma by means of the refractometer and found a decrease in the early stages in the majority of cases. Consequently, they think that the diuresis is secondary to hydremia. In their opinion fluid and salt are first transferred to the blood from the tissues and then excreted by the kidney. The chloride in the plasma was first reduced, the lowest value being obtained in 4 to 6 hours, and later began to rise again. In the cases in which diuresis was arrrested by giving atropine hydremia and hyperchloremia developed. Saxl and Heilig (1923) made some experiments on dogs to which uranium nitrate had previously been given. When novasurol was injected soon after giving uranium, dilution of the blood took place and an increase in the chloride content, followed some hours later by concentration of the blood and diminution in the plasma chloride. Some time later after uranium nephritis became established there was a dilution of the blood and the chloride content was increased. On giving novasurol now diuresis occurred without further dilution or increase in chloride concentration. In still later stages of uranium poisoning the effect of novasurol was to produce polyuria without any increase in the chloride in the urine. At this stage they think novasurol reactivates uraninm.

Nonnenbruch (1921) and Eppinger (1921) confirmed the work of Saxl and Heilig on the changes in the blood and agreed with them in believing that the action of the 
drug is on the extra-renal tissues. Bohn (1923) as the result of experiments on normal and nephrectomised rabbits also obtained evidence of a primary dilution of the blood and agreed with these authors in considering the action extra renal. Tezner (1923) studied the rate of absorption of normal saline solution injected subcutaneously into the instep in children and found that this was absorbed more rapidly when novasurol had been previously administered. This is additional evidence he thinks that the action of the drug is. on the tissues.

Mühling (1921) was unable to confirm the changes found in the blood by the observers just mentioned and believed that the action of novasurol is on the kidney tissue. Klucke (1922) is of the same opinion. Bleyer (1922) on the other hand found the changes in the blood to be so slight that he was unwilling to draw conclusions from them. Brunn (1921) considers that no conclusive evidence has been brought forward as to the site of action, while Fodor (1923) thinks that it acts neither directly on the kidneys nor on the tissues, but on a hypothetical centre in the medulla.which regulates water and chloride metabolism.

An extensive study of the toxic effects of novasurol has been made on syphilitic subjects by Zeiler (1917), who administered 5000 injections to 900 patients. He found that there was vomiting in 2.4 per cent of cases and 0.5 per cent of injections, diarrhoea in 6 per cent of cases and less than 1 per cent of injections, stomatitis in 4 per cent of cases. Fainting occurred in a very small number. From these effects recovery was rapid and they were considered to be of little importance. There was kidney irritation in less than 1 per cent of cases and only in those in which evidence of previous kidney disease existed. He states that albuminuria when present progressively improved even when it had been produced by calomel or grey oil. The only other toxic symptoms which have been described occurred in a few cases in which hemorrhagic colitis appeared. One case of hemorrhagic encephalitis was attributed to the action of the drug. All those who have studied the subject clinically agree that toxicity is infrequent and rarely severe and that there is no evidence of kidney damage unless the kidney has previously been diseased.

The present investigation has been undertaken to study the effect of novasurol on edema in such cases of cardiac disease as were resistant to treatment with diet, rest, and drugs, and to find whether the drug produced any deleterious effects on the organism. The alterations produced in the various constituents of the urine, blood and edema fluid, were also studied with a view to obtaining some light on the mechanism by which the drug acts.

\section{METHOD OF INVESTIGATION}

The patients examined were treated throughout the investigation by rest in bed and salt free diets, except in two cases which received 1 
gram of salt per diem. Their fluid intake was restricted to $1200 \mathrm{cc}$. per diem. Before novasurol was given digitalis was administered until one was assured that no effect on the excretion of urine was obtainable by this means. In four of these patients who were suffering from fibrillation of the auricles, it was thought advisable, in order to study the effect of novasurol under conditions in which as many factors as possible remained constant, to continue the administration of digitalis in amounts sufficient to maintain the ventricles at a constant rate. Digitalis was, however, never given during the test itself. In two cases of auricular fibrillation and in the cases in which the cardiac rhythm was normal, the heart was not under the influence of digitalis when novasurol was being investigated. During the preliminary period of the investigation the urine was collected in 12 hour specimens. In estimating the fluid intake both the actual fluid and food fluid were measured. The volume of urine, specific gravity and the chloride output were determined in each specimen. When the water and chloride output reached a constant level, novasurol was given. In many of the observations the urine was collected in 3-hour periods for 24 hours before and 48 hours after the administration. In these specimens the volume, specific gravity, chloride, and sometimes the urea and ammonia of the urine were estimated. In the interval between injections the volume and chloride of the urine continued to be studied in 12 hour specimens as before. Chloride was estimated by a Volhard titration and urea and ammonia by the method of Van Slyke and Cullen (1914). Specimens of blood taken were $4 \frac{1}{2}$ hours after the administration of novasurol and at the corresponding time on the previous and following days. Four and one half hours after the drug had been given was selected as the time for obtaining the blood samples as at this time the response to novasurol was well established. We estimated urea by the method of Van Slyke and Cullen (1914), and plasma chloride by the method of Van Slyke (1923). The chloride in the plasma and urine were determined in order to study the remarkable changes in salt metabolism reported after novasurol injection. Urea estimations in blood and urine were made primarily to discover whether kidney function was damaged by the drug and secondarily to observe in what way, if any, urea excretion was affected. In many instances we also studied the corpuscular volume by means of the 
hematocrit and the hemoglobin percentage by Haldane's hemoglobinometer. In the cases in which we investigated the question of dilution or concentration of the blood, specimens were taken one half hour after the injection and at frequent intervals up to 7 hours. In these specimens we determined the percentage of protein in the plasma by means of the refractometer, plasma chloride, corpuscular volume and, in some cases, the hemoglobin percentage. When observations were made on the edema fluid this was done by puncturing the tissues with a Southey tube and collecting the fluid which exuded. On such occasions the edema fluid was collected at the same time as the sample of blood and the chloride content of the fluid was estimated by the same method as was used for plasma chloride.

Novasurol was administered in doses of 1 to $2 \mathrm{cc}$. by intramuscular or intravenous injection. In the two cases in which the latter was used there was found to be no advantage in it over the intramuscular method. A preliminary injection of $1 \mathrm{cc}$. was given to guard against the possibility of an idiosyncrasy to the drug. Afterwards injections of 2 cc. were usually employed. The drug was injected into the buttock in most instances, but in those in which there was edema of this region it was injected into some edema-free muscular region, usually the muscles of the back. Injections were not repeated at intervals shorter than four days, except in the case of the injection following the preliminary $1 \mathrm{cc}$; this was given two days later. Previous observers found rapid repetition inadvisable.

\section{OBSERVATIONS}

The cases which we have selected for observation were in the most advanced stages of heart failure. Clearly a new diuretic has its principal advantage if it is shown that with it edema fluid can be removed from cases in which it had been demonstrated that the usual methods of treatment failed. We have administered the drug to eight cases.

Case 1. I. K., Hospital No. 4836. The patient was a man of 37 years of age. On admission he suffered from marked dyspnea and palpitation. He was extremely cyanosed. The heart was enlarged and systolic and diastolic murmurs were heard at the apex. The pulse was rapid and irregular. There was fluid in the right pleural cavity and moist rales were heard over both lungs. The liver was en- 
larged and ascites was present. There was edema of the legs. Digitalis slowed the heart but failed to alter the edema. Diuretin was also unsuccessful. As the result of giving novasurol the patient's clinical condition improved enormously. Dyspnea while in bed disappeared. The cyanosis became much less marked. The peripheral edema, ascites and pleural exudate disappeared and the liver was reduced in size. These tended to recur unless controlled by further injections. The diagnosis was mitral stenosis; auricular fibrillation; acute cardiac decompensation.

Case 2. S. M., Hospital No. 4851. The patient was a man of 31 years of age. On admission he was dyspneic and cyanotic. The heart was enlarged and there were systolic and diastolic murmurs to be heard at the apex. The pulse was rapid and irregular. There were moist râles all over the chest but no fluid in the pleural cavities. The liver was enlarged and there was well marked ascites. There was edema of the legs. Digitalis showed the heart but failed to alter the edema. Diuretin also failed to produce any action. Theocin produced a slight diuresis but caused symptoms of gastric irritation. Novasurol injections produced a marked improvement. Dyspnea and cyanosis disappeared. The edema of the legs, and the ascites disappeared and the liver was reduced in size. Improvement continued without further injections. The diagnosis was mitral stenosis; auricular fibrillation; acute cardiac decompensation.

Case 3. F. S., Hospital No. 4282 . The patient was a female aged 20 years. On admission she was dyspneic and complained of marked palpitation. There was considerable cyanosis. The cardiac pulsation was marked so that the left side of the chest heaved with each beat. The heart was enlarged and systolic and diastolic murmurs were heard all over the chest, especially in the region of the apex. The pulse was rapid and irregular. There was no exudate into the pleural cavities but a few moist râles were heard. The lower border of the liver was mid-way between the umbilicus and pubis. There was neither ascites nor edema of the legs but there was slight edema of the sacral region. Digitalis even in small doses occasioned the onset of pulsus bigeminus and made the clinical condition worse. During previous admissions to hospital she had reacted well to digitalis. Theocin was given without effect. After an injection of novasurol the improvement was striking. Dyspnea disappeared. The color improved and palpitation became slight. The heart rate was reduced, pulsation in the neck was absent and in many instances the size of the liver was reduced $5 \mathrm{~cm}$. This improvement continued for some time after each injection and then the patient would become suddenly worse. Eventually a stage was reached when no response was elicited and the patient died. The diagnosis was mitral stenosis; auricular fibrillation; acute cardiac decompensation.

Case 4. M, D., Hospital No. 4731 . The patient was a colored man aged 48 years. He suffered from severe dyspnea. There was cyanosis of the mucous mem- 
branes. The heart was large and thene were systolic and diastolic murmurs to be beard at the aortic area. The pulse was slow, irregular and water-hammer. There was a considerable amount of fluid in the right pleural cavity. There was slight enlargement of the liver and fluid in the abdominal cavity. There was no edema of the legs. Thoracocentesis was performed on three occasions on account of respiratory distress. The patient was thoroughly digitalized. There was marked improvement in the clinical condition, but fluid persisted in the abdomen. As the result of novasurol injections this was completely removed and has not reaccumulated. The diagnosis was aortic disease; auricular fibrillation; acute cardiac decompensation.

Case 5. S. N., Hospital No. 4971 . The patient was a man aged 38 years. He was nervous and suffered from dyspnea and cyanosis. The pulse was regular. The systolic blood pressure was 152 , the diastolic 120 . The heart was enlarged but there were no murmurs to be heard. There was fluid in the right pleural cavity and moist râles in the lungs. The liver was slightly enlarged and ascites was present. There was edema of the legs. There was no evidence of kidney insufficiency. After giving digitalis diuresis began but this was not maintained sufficiently long to produce a marked reduction in the edema. The clinical condition improved while the diuresis lasted but then a relapse took place. The patient did not react well to the first dose of novasurol and no improvement occurred. The second injection had a better effect and was followed by definite improvement. The patient died suddenly at stool five days after the last injection had been given. His clinical condition appeared better on the day he died than it had been since admission. The diagnosis was essential hypertension; cardiac hypertrophy; acute cardiac decompensation.

Case 6. L. L., Hospital No. 4935 . The patient was a female aged 46 years. She showed the typical symptoms of exophthalmic goitre. She suffered from marked dyspnea and complained of a considerable amount of pain and tenderness over the precordium and left arm. Cyanosis was not marked. The pulse was slow and irregular. The heart was enlarged and a systolic murmur was present at the apex. The sounts were clear at the other areas. There was fluid in the right pleural cavity and ascites was also present. The liver was not enlarged. There was edema of the sacral region and legs. No improvement followed the use of digitalis. Giving theocin resulted in a slight diuresis but was accompanied by symptoms of gastric irritation. An hour after $1 \mathrm{cc}$. of novasurol was given the patient had a rigor lasting a few minutes and the temperature rose to $102^{\circ}$. A little later she vomited; she was uncomfortable for several hours but quickly recovered. A definite diuresis occurred and next day the patient felt better than before the injection. No further injections were given. The diagnosis was exophthalmic goitre; auricular fibrillation; cardiac decompensation. 
Case 7. C. R. Rospital No. 4267. The patient was a male aged 55 years. He suffered from marked dyspnea and cyanosis. The pulse was moderately rapid and totally irregular. The heart was enlarged. No murmurs were heard. There were sibilant rhonchi in the lungs but no moist rales were heard. The liver was enlarged and there was well marked ascites. There was considerable edema of the legs and sacral region. The patient showed progressive improvement under digitalis. Novasurol was administered during this period but there was no evidence that any part of the subsequent improvement was due to it. The diagnosis was chronic myocarditis; auricular fibrillation; acute cardiac decompensation.

Case 8. A. B., Hospital No. 4919. The patient was a woman aged 44 years. The outstanding symptom was tremendous abdominal distention due to ascites. This had necessitated tapping every three weeks since its onset one year and eight months ago. The patient suffered from dyspnea on exertion and this became marked when ascites was extreme. Cyanosis was slight but increased in proportion to the abdominal distention. Slight precordial pain was present when the abdomen was tense. The pulse was regular. The heart was greatly enlarged and systolic and diastolic murmurs were heard at the apex. The lungs showed no abnormality. The liver was enlarged. There was considerable edema of the legs and sacral region., No benefit followed the use of digitalis. Ascites progressively increased and relief was obtained only by abdominal puncture. Immediately before tapping novasurol was given with some increase in urine output. A second injection produced practically no effect. There was no alteration in the clinical condition. The day after the second injection 13 liters were removed by abdominal puncture. Novasurol injections were not repeated. The diagnosis was mitral stenosis; cardiac decompensation; perihepatitis.

Summary. These then were cases of severe heart failure in which edema was a prominent symptom. In six cases satisfactory diuresis followed the injection of novasurol. In Case 7 there was no effect from the administration; this case exhibited an increased urine volume following digitalis administration and novasurol was given to see whether it could produce an increase in this diuresis. This did not take place. In Case 8 the effect was very slight.

\section{RESULTS}

\section{Changes in the body weight}

In every case in which marked diuresis occurred there was a corresponding fall in weight (table 1 and fig. 1). The fall sometimes continued for a few days after the administration. The greatest 
fall in weight on the day immediately following an injection was 3 kilograms. Usually it was 1 to 2 kilograms. In the interval between injections there was often a slight gain in weight.

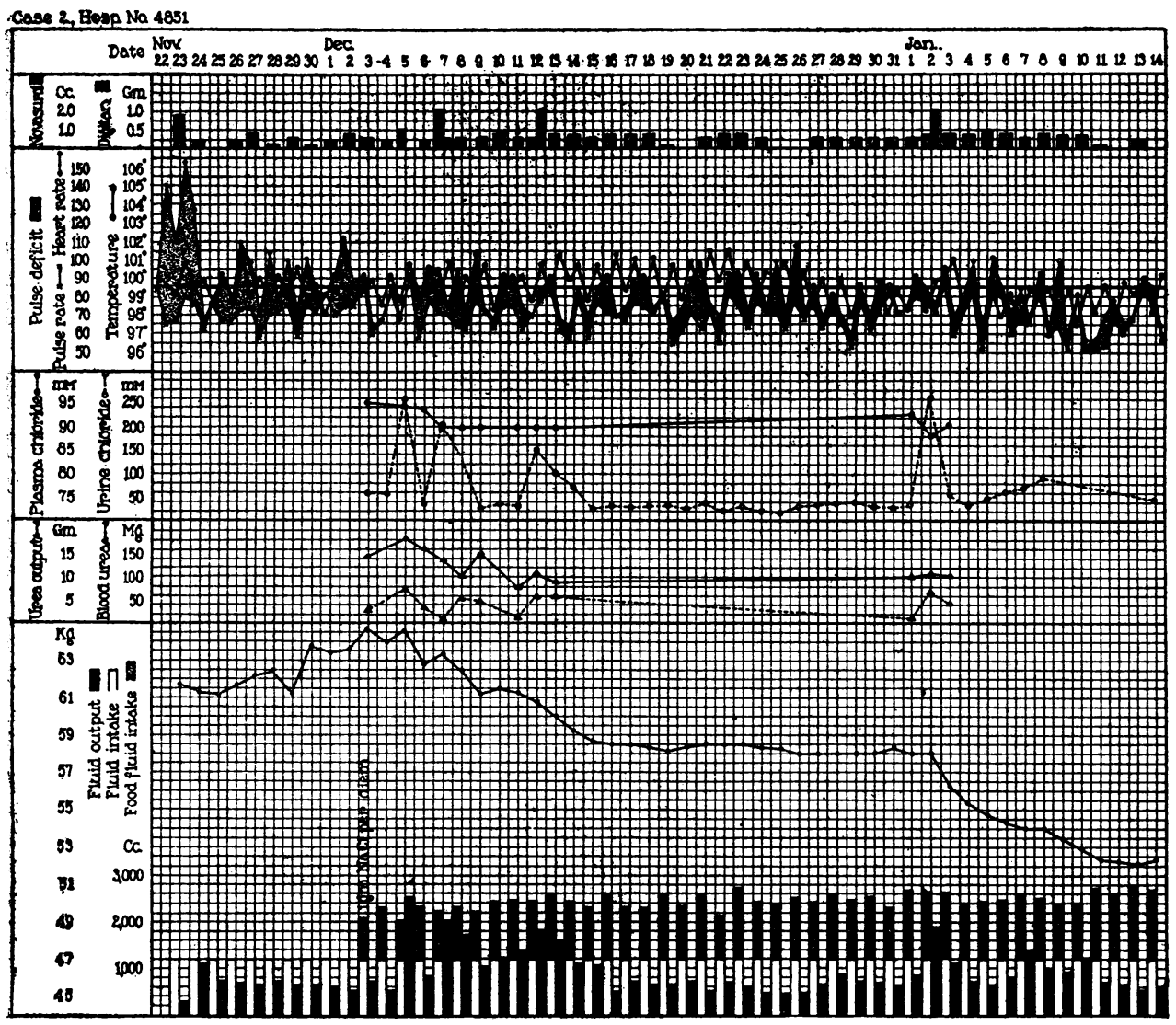

Fig. 1. The Effect of Novasurol Administration Throughout the Course of Treatment (Case 2)

\section{Changes in the urine}

Volume. The volume of urine excreted varied, but in all cases it increased after giving novasurol to a point above the previous level (table 1 and fig. 1). The only exception was Case 7, in which diuresis was already in progress as the result of giving digitalis. Before the administration of the drug the urinary output was usually very small, 
being about 300 to $400 \mathrm{cc}$. per diem. After the administration, in many cases this was remarkably increased. The degree of diuresis which resulted varied with the dose. The maximum effect following the injection of $1 \mathrm{cc}$. was $1884 \mathrm{cc}$, but the usual result was from 1000 to $1500 \mathrm{cc}$. After $2 \mathrm{cc}$. the maximum volume was $3316 \mathrm{cc}$. As a rule,

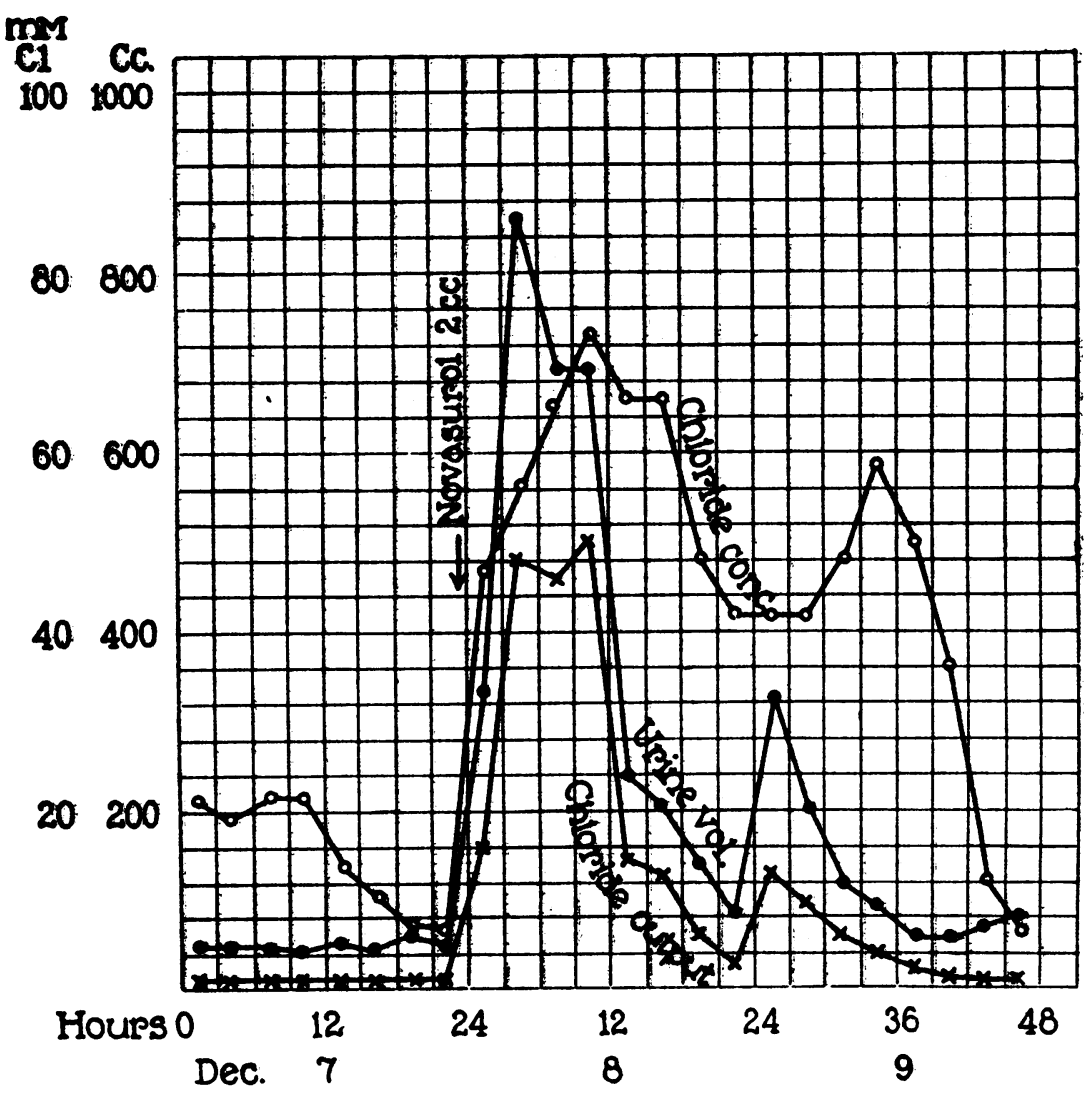

Fig. 2. The Urine Volume, Total Chlorme Excretion and Chloride ConCENTRATION FOR 24 Hours Before aNd 48 Hours after Novasurol

the output varied from 1500 to $3000 \mathrm{cc}$. In three cases, although there were definite increases in amount, a reaction as satisfactory as in the other cases did not take place.

Diuresis usually began within the first three hours after the injection of the drug and rapidly attained a maximum in 6 to 9 hours. In cases 
where the circulation was more sluggish, the onset of diuresis appeared to be delayed. After attaining a maximum, it gradually fell again until it regained its previous level. This was reached in most cases within 24 hours. In a few cases, however, the augmentation was maintained to a slight extent for another day. There was practically no difference in the rapidity of action between intravenous and intramuscular administration.

Chloride. One of the most striking effects of novasurol was the remarkable increase of chloride in the urine (table 1). Not only was there an absolute increase in the amount excreted, but the concentration in the urine increased as well (fig. 2). The extent of the increase is in fact much greater than that described by Cushny (1917) as following the administration of other diuretics. Before the injection of the drug the chloride output was very small, being less than 50 millimols per diem in almost every case and in many instances, being much less than this. As a result of giving novasurol, the maximum output in 24 hours which was observed was 314.65 millimols. Usually the chloride excretion increased to about 200 millimols per diem. The chloride excretion followed closely the curve of water excretion as to time, except that on the day after injection a slight increase of chloride was more frequently maintained than an increase in water. Two days after the injection the chloride output had invariably fallen to its previous level, and in many cases to a lower level.

Urea and ammonia. The excretion of urea and ammonia was studied in the 3 hour specimens of urine corresponding to the blood specimens. In three instances urea and ammonia were estimated in 3 hour specimens throughout the 24 hours preceding and the 48 hours following the administration of novasurol. No constant alteration has been observed in the amounts in the urine (table 1). During diuresis the concentration of urea was always considerably reduced but the total output varied. We observed that in some cases the output of urea was greater on the day following than on the day of the injection. The ammonia in the urine showed no constant changes. It varied in the same patient on different occasions. The changes in these constituents were so small that it is evident that the drug has little action on their excretion.

Abnormal urinary changes. In all cases observations have been 


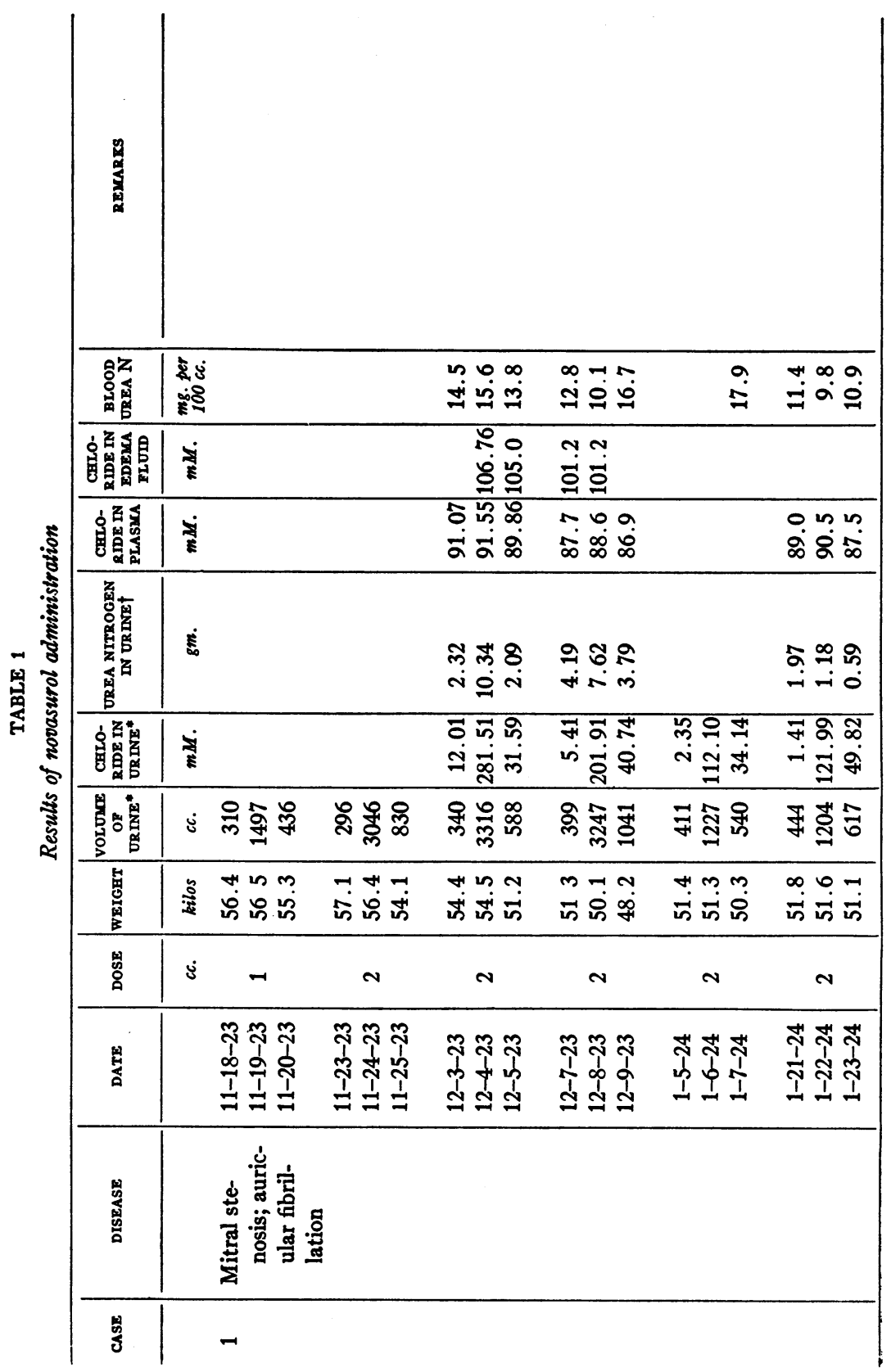




\begin{tabular}{|c|c|c|c|c|c|}
\hline 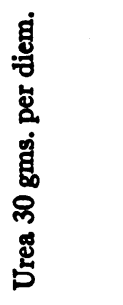 & 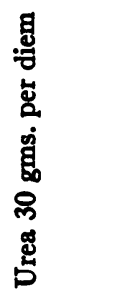 & & & & \\
\hline 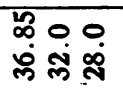 & $\begin{array}{l}\infty 0 \\
\text { N่ } \\
\text { สุ }\end{array}$ & 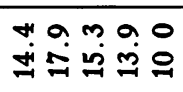 & $\hat{\infty} \stackrel{\infty}{\infty} \stackrel{0}{0} 0$ & مُ0. & 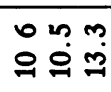 \\
\hline & & 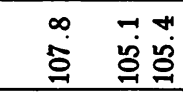 & & & \\
\hline ॠே0 & $\begin{array}{l}n 0 \\
\infty \\
\infty\end{array}$ & 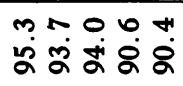 & 요 & वे $\frac{a}{\infty}$ & 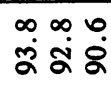 \\
\hline 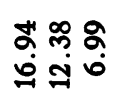 & $\begin{array}{l}\circ 80 \\
=0\end{array}$ & 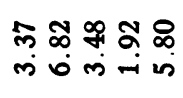 & 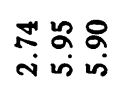 & ד્ & 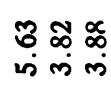 \\
\hline 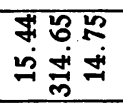 & & 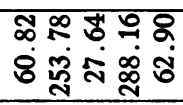 & 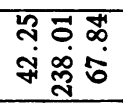 & 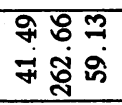 & 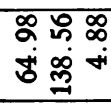 \\
\hline 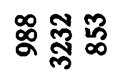 & 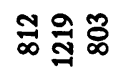 & 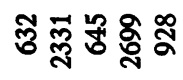 & ్ㅗㅋㅋㅀ욬 & $\stackrel{\sharp}{\sharp}$ & ㅇํㅇ 举 F \\
\hline 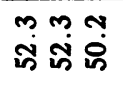 & 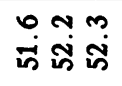 & 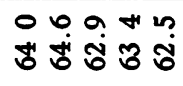 & m & 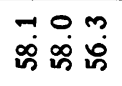 & 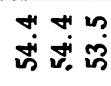 \\
\hline$N$ & - & $-N$ & $N$ & $N$ & $\rightarrow$ \\
\hline \multirow[t]{3}{*}{ 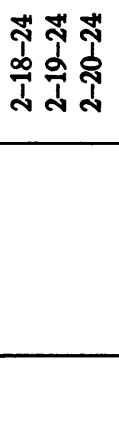 } & 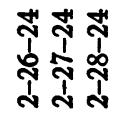 & 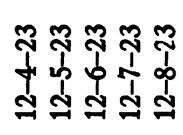 & 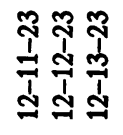 & 志志志 & 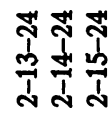 \\
\hline & & 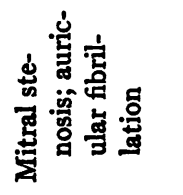 & & & \\
\hline & & N & & & \\
\hline
\end{tabular}




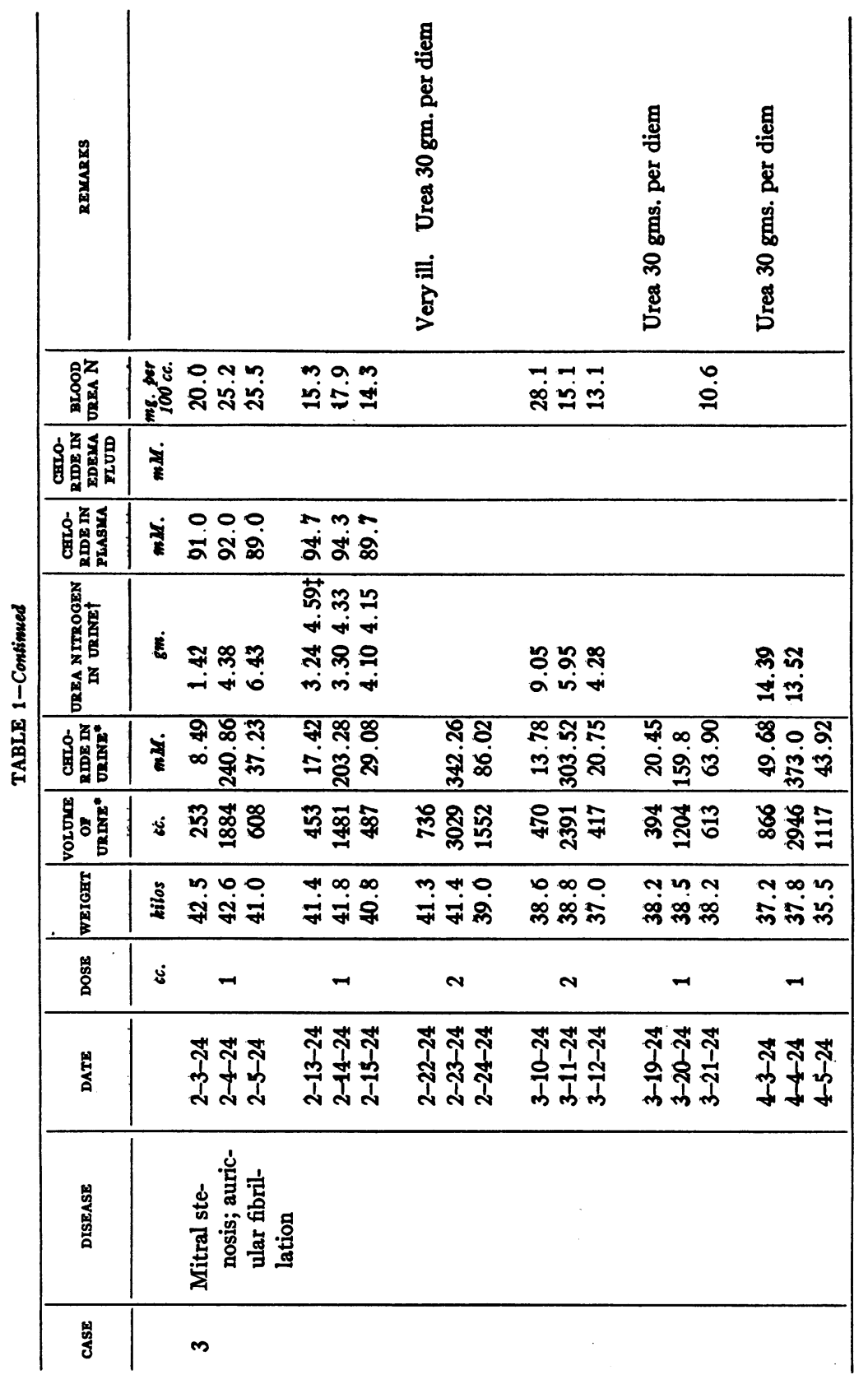




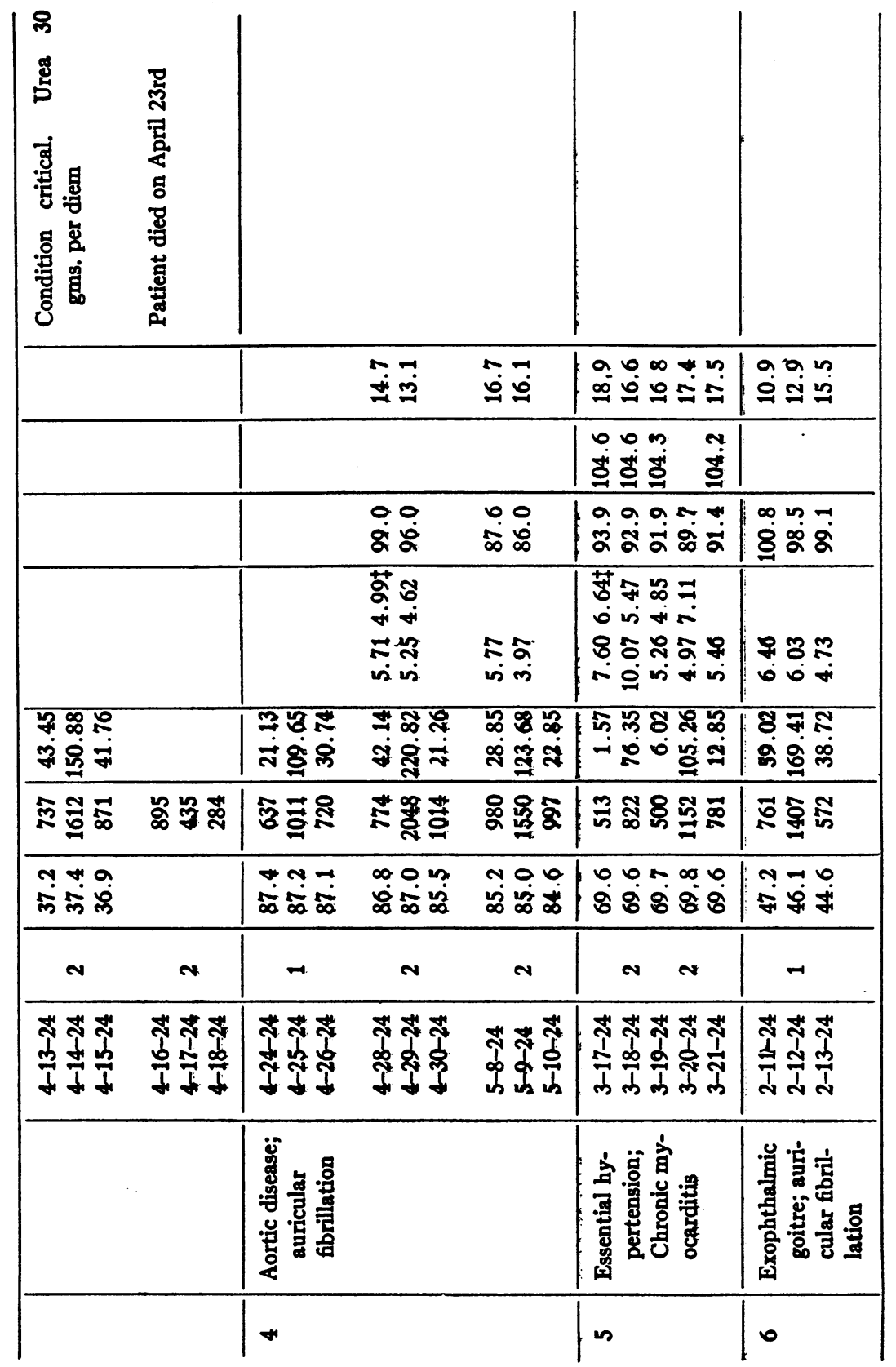




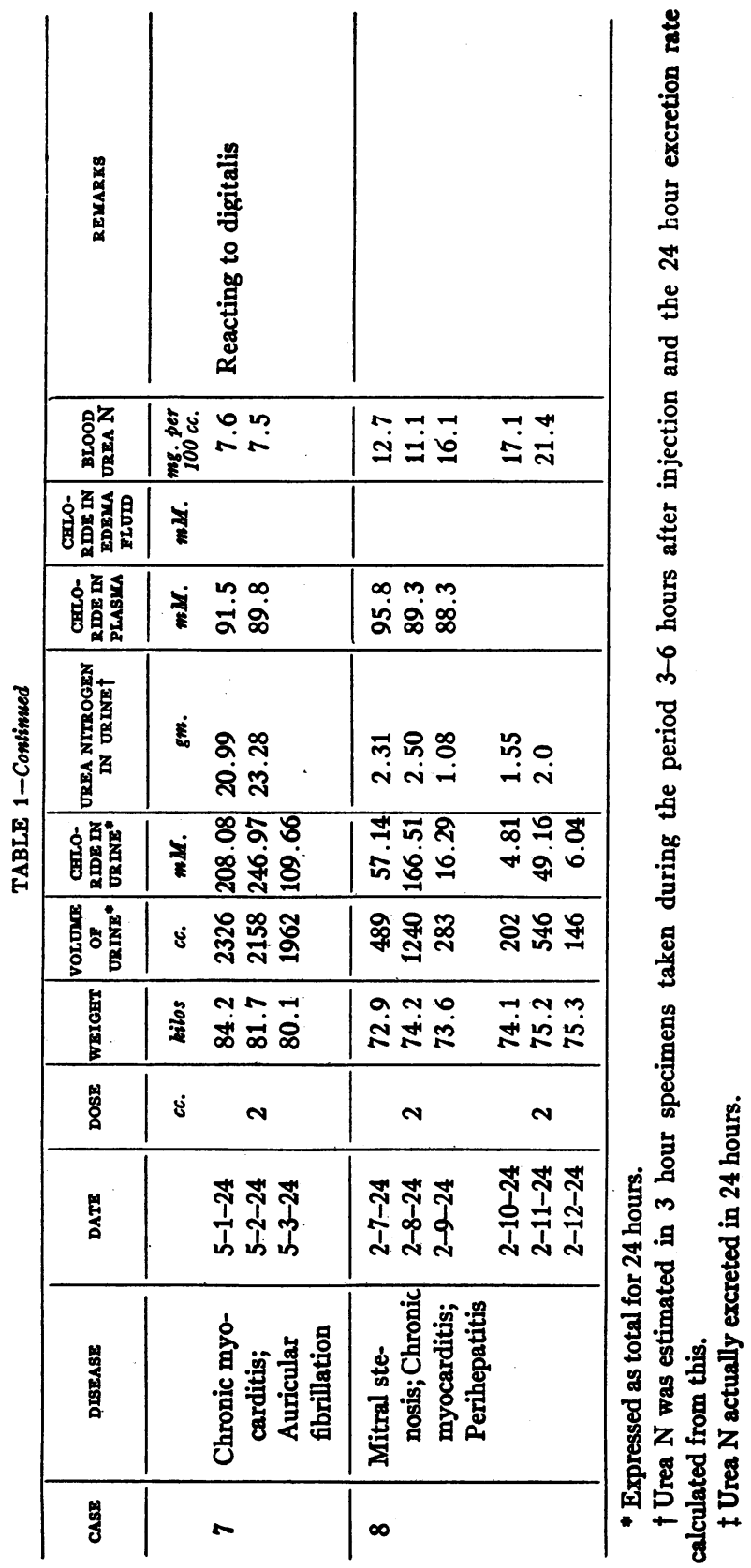


made daily to see whether there was any evidence of kidney damage as shown by the presence of albumin, casts or red blood cells in the urine. This evidence was completely absent during the period of the investigation which in most cases extended over some months. When these signs were absent previous to the injection they did not appear subsequently. When they were present before they always tended to disappear so indicating improvement.

\section{Changes in the blood}

Plasma chloride. The chloride content of the plasma has been determined in each case at a period of $4 \frac{1}{2}$ hours after the administration of the drug. In most cases there was a slight fall at this period (table 1). On the day following the injection it was invariably lower than before injection. In the interval between injections there was usually a rise towards the original level.

Three observations have been made in which specimens were taken frequently throughout the day of the injection (tables 2 and 3 , fig. 3 ). Two of these were made on patients, and one on a dog. In the two observations on patients a steady fall took place in the plasma chloride after novasurol was injected and this attained its maximum within $3 \frac{1}{2}$ hours; thereafter there was a slow rise. In the dog there was on the contrary a preliminary rise which reached its height $1 \frac{1}{2}$ hours after injection, then a fall which attained its maximum at $4 \frac{1}{2}$ hours and finally a subsequent rise.

Urea. The urea in the blood also varied considerably (table 1). In some cases it was slightly higher and in others slightly lower during the day of injection. The next day in the majority of cases, however, it was lower than before injection. The blood urea appears to be influenced only in so far as the drug affects the efficiency of the circulation.

Protein content of the plasma. We have made observations in three instances throughout the day of injection on the amount of protein in the blood plasma by means of frequent refractometer readings. The observations extended from half an hour to seven hours after the injection. The first effect was found to be a fall in the concentration of protein, occurring within an hour and a half after the injection (tables 2 and 3, fig. 3). In one case it reached its maximum in half an hour, 


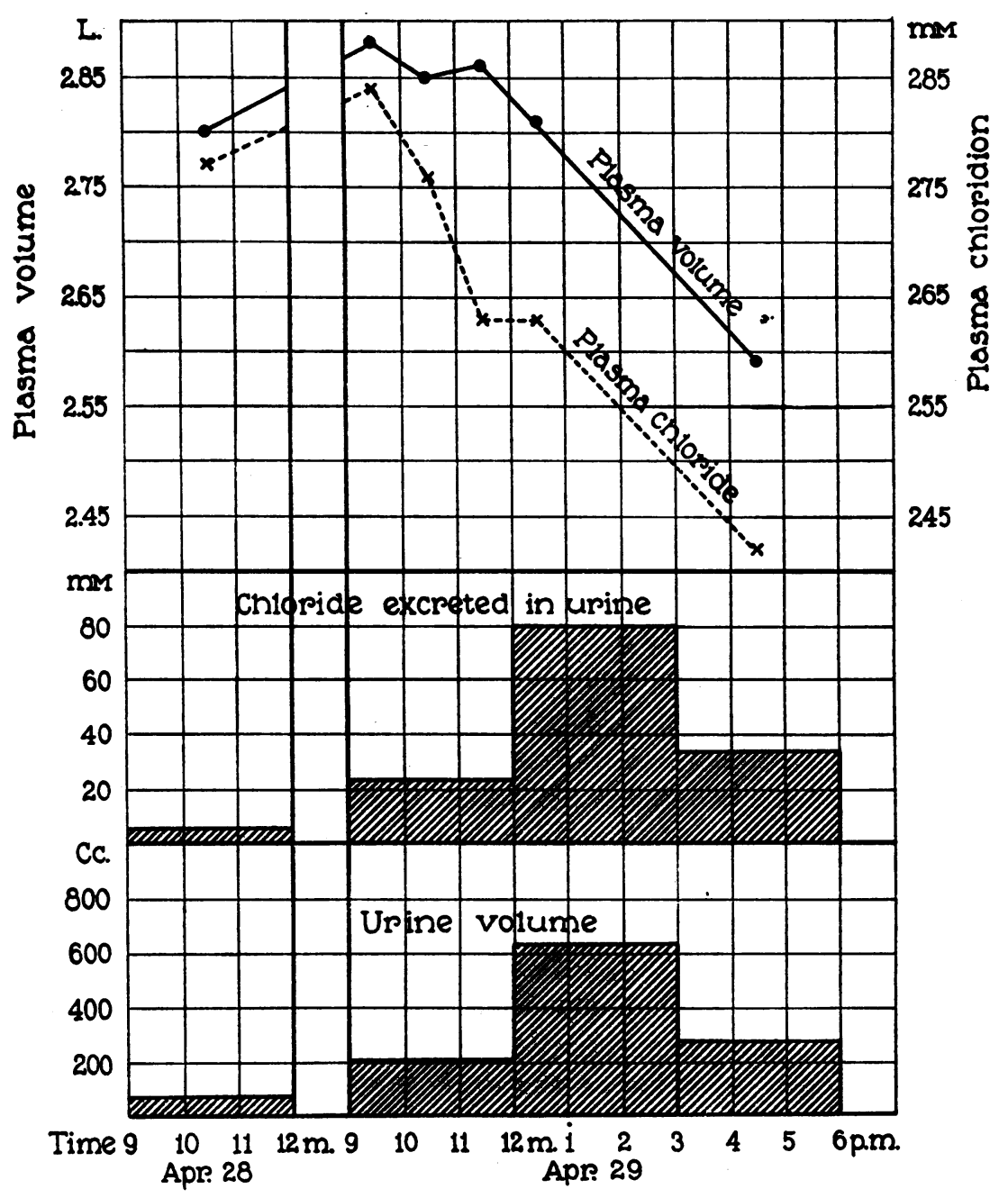

Fig. 3. The Change in Plasma Volume, Plasma Chloride, Chlorme ExCRETION AND URINe Volume AfTer NovasUrol

For explanation see text 
in another in an hour and a half, and in another in about two and a half hours. There was greater diuresis on the occasion when the lessened concentration took place early. After about two and half hours it began to rise again and continued to do so until in the later stages the blood became much more concentrated than it had been previous to the injection.

Corpuscular volume. In most of the observations the volume of the cells in the blood was estimated $4 \frac{1}{2}$ hours after the administration of the drug and in every case the blood was found to be slightly more concentrated than it had been previously. In one case in which refractometer readings were made at irregular short intervals throughout the day the corpuscular volume was studied at the same time and was found to follow the same curve as the refractometer readings (table 2).

Hemoglobin percentage. Readings of the percentage of hemoglobin were taken in most instances $4 \frac{1}{2}$ hours after injection and in every case a slight increase was found. In two cases readings were made throughout the day and in both a primary lowering of the percentage was followed by an increase above the level before the drug was given (table 2). In one case the protein, corpuscles and chloride were also estimated (table 2).

\section{Changes in edema fluid}

Chloride. The chloride in the edema fluid $4 \frac{1}{2}$ hours after novasurol administration was altered in the same direction as that of the plasma, though the changes observed were slightly less marked. A continuous slight fall always occurred and this was maintained in the interval between the injections in contrast to its behavior in the plasma.

\section{Evidences of toxicity}

In only one case, a woman, have we had any evidence of an idiosyncrasy to the drug. This was the case of exophthalmic goiter referred to in the protocols (Case 6). She suffered shortly after the injection from rigor, rise of temperature and vomiting, but recovered rapidly from these symptoms. In a few cases there was been complaint of slight headache on the day the injection was given, and sometimes a slight rise in temperature that evening, both being absent the next day. 
TABLE 2

Effect of novasurol injection on plasma protein, plasma chloride, corpuscular volume and hemoglobin percentage

\begin{tabular}{|c|c|c|c|c|c|c|c|c|c|}
\hline ฮू & 亗 & 总 & 总 & 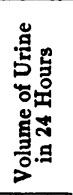 & 胥 & 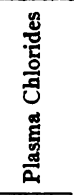 & 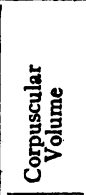 & 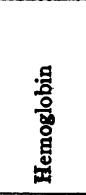 & Remarks \\
\hline 4 & $\begin{array}{l}5-8-24 \\
5-9-24\end{array}$ & $\begin{array}{c}10.30 \\
10.30 \\
11.30 \\
2.0 \\
4.0\end{array}$ & 2 & $\begin{array}{c}c c . \\
907 \\
1476\end{array}$ & $\begin{array}{c}\text { per cent } \\
7.59 \\
7.46 \\
7.24 \\
7.20 \\
8.39\end{array}$ & $\begin{array}{l}m M . \\
87.6 \\
86.0 \\
85.3 \\
86.6\end{array}$ & $\begin{array}{c}\text { per cent } \\
43.0 \\
40.5 \\
39.0 \\
41.0 \\
60.0\end{array}$ & $\begin{array}{r}\text { per cent } \\
95.5 \\
94.0 \\
90.0 \\
92.5 \\
100.0\end{array}$ & $\begin{array}{l}\text { Novasurol } 2 \text { cc. at } \\
9.0 \text { a.m. }\end{array}$ \\
\hline
\end{tabular}

TABLE 3

The effects of novasurol administration on plasma volume and chloridion content

\begin{tabular}{|c|c|c|c|c|c|c|}
\hline Date & Time & 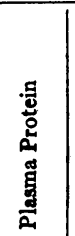 & 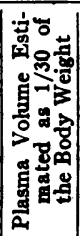 & 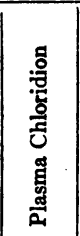 & 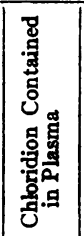 & Remarks \\
\hline \multirow{7}{*}{ May 13} & & $\begin{array}{l}\text { per } \\
\text { cent }\end{array}$ & liters & $\begin{array}{c}m M \\
\text { per } \\
\text { liter }\end{array}$ & $m M$ & \multirow{7}{*}{$\begin{array}{l}\text { Normal dog weighing } 11.4 \mathrm{~kg} \text {. given } \\
1 \mathrm{cc} \text {. novasurol intramuscularly at } \\
9.45 \\
\text { Shift of chloridion to plasma from } \\
\text { tissues } \\
\text { Shift of chloridion to plasma from } \\
\text { tissues } \\
\text { Loss of chloridion in urine } \\
\text { Loss of chloridion in urine } \\
\text { Loss of chloridion in urine }\end{array}$} \\
\hline & 9.30 a.m. & 6.87 & 0.380 & 103.6 & 39.4 & \\
\hline & 10.15 a.m. & 6.87 & 0.380 & 105.0 & 39.9 & \\
\hline & 11.15 a.m. & 6.48 & 0.403 & 106.0 & 42.7 & \\
\hline & 12.15 p.m. & 7.30 & 0.358 & 102.4 & 36.7 & \\
\hline & 2.15 p.m. & 8.22 & 0.318 & 98.7 & 31.4 & \\
\hline & 4.15 p.m. & 8.55 & 0.305 & 99.8 & 30.4 & \\
\hline April 28 & 10.30 a.m. & 7.07 & 2.80 & 99.0 & 277.0 & $\begin{array}{l}\text { Case } 4 \text {, given } 2 \text { cc. novasurol intra- } \\
\text { muscularly at } 9 \text { a.m. Apr. } 29 \text {. }\end{array}$ \\
\hline \multirow[t]{5}{*}{ April 29} & 9.30 a .m. & 6.88 & 2.88 & 98.6 & 284.0 & $\begin{array}{l}\text { Shift of chloridion to plasma from } \\
\text { tissues }\end{array}$ \\
\hline & 10.30 a.m. & 6.94 & 2.85 & 96.8 & 276.0 & $\begin{array}{l}\text { Shift of chloridion to plasma from } \\
\text { tissues }\end{array}$ \\
\hline & 11.30 a.m. & 6.92 & 2.86 & 91.9 & 263.0 & Loss of chloridion in urine \\
\hline & 12.30 p.m. & 705 & 2.81 & 91.9 & 258.0 & Loss of chloridion in urine \\
\hline & 4.30 p.m. & 7.63 & 2.59 & 93.4 & 242.0 & Loss of chloridion in urine \\
\hline
\end{tabular}


There has been complaint occasionally of slight pain at the site of injection, which rapidly disappeared. No indurated nodules have persisted. On one occasion a small quantity of the drug escaped subcutaneously and produced extreme irritation with the subsequent development of a small necrotic area in this region. Healing, however, took place promptly. We have seen no evidence of salivation but it seems important that strict attention should be paid to the state of the mouth before and during the administration of the drug.

\section{SUMMARY}

Novasurol has been administered in doses of 1 to $2 \mathrm{cc}$. to eight patients suffering from heart failure. In the majority of cases decided improvement in the clinical condition took place and with one exception no untoward effect occurred. There is no evidence that any damage was done to the kidney. Diuresis commenced within the first 3 hours, reached its height in 6 to 9 hours and terminated usually in 24 hours. The output of chloride followed the same curve as the water output, but was increased to an even greater extent. The chloride in the plasma and in the edema fluid showed a fall subsequent to the injection. The fall was slightly less in the case of the edema fluid. No marked alteration was found in the blood urea or in the amount of urea or ammonia excreted. The protein content of the plasma, the corpuscular volume and the hemoglobin percentage all showed a primary fall which was maximum in $2 \frac{1}{2}$ hours and was followed by an increase which reached a greater height than that obtained before the injection.

\section{DISCUSSION}

In the investigation of a new therapeutic agent it is desirable to learn whether the new remedy has properties not possessed by the drugs already in common use. If it has not it is an unnecessary addition to an already overburdened list. The standard which has naturally to be applied is the evidence of clinical improvement. Too frequently we are dependent on the subjective symptoms which the patient experiences and then relates to us. In edema, however, one has the advantage of being able to study the rate of disappearance of the accumulated fluid and also the fall in weight of the patient which 
accompanies its diminution. The removal of a certain amount of excess fluid from the body is of itself in most cases advantageous but even if the removal takes place it is desirable to see that there are no after effects of the drug which nullify or counterbalance the good effect which stimulating diuresis brings about. For these reasons we selected for treatment cases in the most advanced stage of heart failure in which there had been no benefit from drugs already available such as digitalis, theocin and diuretin. The results obtained in some cases were spectacular, while usually good results have been obtained. In no case has the patient's clinical condition changed for the worse.

It is necessary since novasurol contains mercury to be certain that it produces no deleterious effect on the kidneys. We have studied this point and have been unable to obtain any evidence of renal injury. From the point of view of its effectiveness, however, it appears to be better not to administer the drug more frequently than every four days. Better results are in fact obtained in this way for the amount of urine excreted tends to diminish when the drug is repeated at too short an interval. The first injection should be small in order to ascertain whether an idiosyncrasy to the drug exists.

This drug, besides having a definite action on the water output of the body, seems to have an even greater effect on its salt metabolism. We have obtained no evidence that there is any alteration in protein metabolism.

That phase of its action which has created most interest in the discussion of its pharmacology is whether the drug has its effect on the kidneys of on extra-renal tissues. The advocates of extra-renal action say that there is evidence of dilution of the blood, and conclude that there must be a primary removal of water and salt from the tissues to the blood from which it is only removed by the kidneys because of its excess in the blood. Those who oppose this view state that they can find no evidence of dilution of the blood. Our results show quite consistently that there is a primary dilution of the blood which attains its maximum within the first three hours and then that there is a swing in the opposite direction, so that for the greater part of the period during which diuresis takes place there is really a concentration of the blood. In so far as there is primary dilution of the blood, we agree with Saxl and Heilig (1922, 1923), Nonnenbruch (1921) and 
Eppinger (1921). They are of opinion, however, that this is the main factor in the action of novasurol and from this circumstance are led to infer that the action must be on extra-renal tissues and that the kidneys in fact play only a passive rôle. With this view we cannot agree in so far as the main action is concerned but we think their view applicable to the first stage. The primary dilution of the blood might be due to one of two causes, either to the passage of water from the tissues to the blood, or to a lessened output of water by the kidneys. As a matter of fact, a slightly lessened output has been observed in rare instances during the first three hours after injection, but the extent of this is never great enough to account, in itself, for the primary dilution of the blood. We are, therefore, driven to the conclusion that in the early stages fluid must pass into the blood from the tissues. The duration of the dilution of the blood is comparatively short and for the greater part of the period of diuresis there is concentration of the blood. This is clearly shown in our determinations and has been almost invariably found by the other observers who have followed the changes in the blood for a sufficiently long period. The fact that diuresis continues while the blood is concentrated seems to us incompatible with the view that the kidneys are merely removing an excess of fluid obtained from the tissues. They are really playing an active part in the process.

The nature of the changes which occur in the chloride of the body fluids during novasurol diuresis is of considerable interest. Here again the first response to the drug appears to be a shift of chloridion from the tissue fluids to the blood stream. Then, as diuresis becomes established and a rapid excretion of chloride occurs in the urine, the chloride of the plasma quickly decreases in amount (table 3).

Determinations of the changes in the chloride concentration of the edema fluid have not been numerous enough for definite conclusions to be drawn on the mechanism which is involved in initiating the shift of salt from tissues to the blood beyond the fact that the chloride content is definitely lowered after diuresis. A study of the ionic strengths of the plasma and edema fluids before and during the early shift of the water and chloridion from the tissues to the blood stream might throw some light on this interesting phenomenon.

An attempt to analyse the changes occurringin salt and water metab- 
olism during novasurol diuresis has been made. If one assumes that the original volume of the plasma is any definite amount, it is possible to calculate values for the changes in the plasma volume and its chloride content. These values must not be regarded as necessarily true but may be used to express relative changes from the original condition of the plasma before the administration of the diuretic. It has been assumed for the purposes of illustration (table 3) that the plasma volume was originally represented by $1 / 30$ of the normal bodyweight and that the percentage of plasma protein varies inversely with the plasma volume. One can plainly observe (fig. 3) an early increase in the volume of the plasma and the chloride contained in it. Then, as chloride and water were excreted in the urine, these quantities decreased rapidly and reached values much below their original level. Nevertheless, diuresis and increased chloride output were maintained in spite of an actual decrease in plasma volume and a diminution in its chloride concentration.

It seems necessary to conclude, therefore, that the drug acts not only on the kidneys but also on the tissues which contain the edema fluid. The action on the tissues is manifest for a comparatively short period only after the drug has been administered, and is shown by definite changes in the composition of the blood. Soon, however, the action on the kidneys becomes apparent, as shown not only by diuresis, but also by changes in the blood which are opposite to those occurring during the first period. During the greater part of the drug's action, indeed, the effect on the kidneys completely dominates the picture, and quite obscures the evidence of extra-renal action.

\section{CONCLUSIONS}

1. Novasurol in doses of 1 to $2 \mathrm{cc}$. injected intramuscularly or intravenously brings about marked diuresis in cases of cardiac edema which have failed to respond to other therapeutic agents.

2. Toxic symptoms are rare and transient. There was no evidence in our cases of renal irritation.

3. Diuresis commences within the first 3 hours, attains its height in 6 to 9 hours, and usually ends in 24 hours. There is a marked increase in the excretion of chloride. This action is even more marked than 
that on water excretion. In their time relations these two effects follow each other closely. There is no evidence of any action on protein metabolism.

4. The drug acts both on the kidneys and on the extra-renal tissues. For a short period after administration the action on the tissues predominates, but for the greater part of the diuresis the action on the kidneys is more important.

\section{BIBLIOGRAPHY}

Bleyer, L. Klin. Wchnschr., 1922, 1,1940. Erfahrungen über die Novasuroldiurese. Bohn, H. Klin. Wchnschr., 1923, ii, 352. Experimentelle Studien über die diuretische Wirkung des Novasurols.

Brunn, F. Munch. Med. Wchnschr., 1921, lxviii, 1554. Zur Wirkung des Novasurols als Diuretikum.

Cushny, A. R. The Secretion of Urine. London. 1st edition. 1917. 184-5.

Eppinger, H. Therap. d. Gegenwart., 1921, xxiii, 81. Utber die sogenannte Myodegeneratio cordis.

Ferriar, J. An Essay on the Medical Properties of Digitalis Purpurea or Foxglove. Manchester. 1799.

Fodor, E. Med. Klin., 1923, xix, 684. Uber das Indikationsgebiet des Novasurols als Diuretikum.

Jendrassik, E. Deut. Arch. f. klin. Med., 1886, xxxviii, 499. Das Calomel als Diureticum.

Jendrassik, E. Deut. Arch. f. klin. Med., 1891, xlvii, 226. Weitere Untersuchungen über die Quecksilberdiurese.

Kollert, V. Therap. d. Gegenwart., 1920, xxii, 340. Uber die diuretische Wirkung des Novasurols.

Kluche, E. Klin. Wchnschr., 1922, i, 622. Novasurol als Diureticum.

Mühling,A. Munch. Med. Wchnschr., 1921, lxviii, 1447. Studie über die diuretische Wirkungweise von Quecksilber. Ausgeführt mit dem organischen Quecksilberpräparet Novasurol.

Nonnenbruch, W. Munch. Med. Wchnschr., 1921, lxviii, 1282. Ueber die Wirkung des Novasurols auf Blut und Diurese.

Saxl, P., and Heilig, R. Wein. klin. Wchnschr., 1920, xxxiii, 943. Ueber die diuretische Wirkung von Novasurol und anderen Quecksilberinjectionen.

Saxl, P., and Heilig, R. Wein. Arch. f. inn. Med., 1921-22, iii, 141. Uber die Novasuroldiurese.

Saxl, P., and Heilig, R. Zeit. f. ges. exper. Med., 1923, xxxviii, 94. Uber die Novasuroldiurese.

Tezner, O. Med. Klin., 1923, xix, 788. Zum Mechanismus der Novasurolwirkung. 
Van Slyke, D. D., and Cullen, G. E. Jour. Biol. Chem., 1914, xix, 211. A Permanent Preparation of Urease and Its Use in the Determination of Urea.

Van Slyke, D. D. Jour. Biol. Chem., 1923, lviii, 523. The Determination of Chloride in Blood and Tissues.

White, E. C. Industrial and engineering chemistry., 1924, xvi, 1034. New Organic Mercurials and Their Therapeutic Application.

Zeiler, K. Munch. Med. Wchnschr., 1917, lxiv, 1257. Novasurol ein neues Quecksilbersalz zur Syphilisbehandlung, mit Bemerkungen über die Grundsätze der Quicksilberhandlung. 